\title{
Estudio de la teoría de despolarización catódica con permeación de hidrógeno y la bacteria Desulfovibrio desulfuricans
}

\author{
M.F. de Romero,****, Z. Duque*, O.T. de Rincón*, O. Pérez" e I. Araujo**
}

Resumen En este trabajo se estudió la permeación del hidrógeno proveniente de una cepa pura de bacterias sulfato reductoras-BSR (Desulfovibrio desulfuricans ssp. desulfuricans), utilizando para ello el tipo de celda de permeación de hidrógeno y una lámina de paladio (Pd). Esto se hizo con la finalidad de evaluar la despolarización catódica como mecanismo de acción de las BSR en la corrosión inducida microbiológicamente. Los ensayos de permeación se realizaron $\sin$ y con polarización catódica, utilizando un medio de cultivo estéril desaireado e inoculado con $10 \%$ de BSR a una concentración de $10^{8} \mathrm{cel} / \mathrm{ml}$. Los resultados obtenidos indicaron crecimiento en $10^{9}-10^{10} \mathrm{cel} / \mathrm{ml}$ a las $18 \mathrm{~h}$ tanto en los ensayos sin polarización como en aquellos con polarización, lo cual refleja que la BSR se desarrolla independientemente de una superficie polarizada como fuente de $\mathrm{H}^{0}$, generando $\mathrm{H}_{2} \mathrm{~S}$ como producto final de la respiración anaeróbica. También, se determinó que sin polarización catódica no existen las condiciones para que el $\mathrm{H}^{+}$, generado por la disociación del $\mathrm{H}_{2} \mathrm{~S}$, se reduzca y permee. Mientras que, aplicando polarización catódica, se observó un aumento en la corriente de permeación, lo cual estuvo asociado a la fase de máxima actividad enzimática de la bacteria.

Palabras clave Celda de permeación de hidrógeno. Polarización catódica. Bacterias sulfato reductoras (BSR). Corrosión inducida microbiológicamente (MIC).

\section{Study of the cathodic despolarization theory with hydrogen permeation and the bacteria Desulfovibrio desulfuricans}

Abstract

Keywords

\begin{abstract}
A Desulfovibrio desulfuricans ssp. desulfuricans (SRB) was used to study the permeation of hydrogen, using a Devanatan and Stachurski cell and a palladium sheet. The aim was to evaluate cathodic depolarization as a Sulfate-Reducing Bacteria action mechanism in Microbiologically Induced Corrosion. The permeation tests were run with and without cathodic polarization, using a sterile deaerated culture medium inoculated with $10 \%$ SRB concentrated at $10^{8} \mathrm{cell} / \mathrm{ml}$. The results indicate bacterial growth in the order of $10^{9}-10^{10}$ $\mathrm{cel} / \mathrm{ml}$ after $18 \mathrm{~h}$ both in the polarized and non-polarized tests, indicating that SRB developed regardless of the surface polarized as a source of $\mathrm{H}^{0}$, generating $\mathrm{H}_{2} \mathrm{~S}$ as a product of the anaerobic respiration. It was also determined that, without cathodic polarization, the conditions are not enough to reduce the $\mathrm{H}^{+}$generated by the $\mathrm{H}_{2} \mathrm{~S}$ dissociation ( $\mathrm{Pd}$ is not susceptible to corrosion at this condition). On the other hand, cathodic polarization increased the permeation current, which was associated with the maximum enzymatic activity phase of the bacteria.
\end{abstract}

Hydrogen permeation cell. Cathodic polarization. Sulfate reducing bacteria (SRB). Microbiological induce corrosion (MIC).

\section{INTRODUCCIÓN}

Las Bacterias Sulfato Reductoras (BSR) desempeñan un papel muy importante en la Corrosión In- ducida Microbiológicamente (MIC), ya que acelera y/o promueve el proceso electroquímico en cualquier ambiente donde se presenten condiciones favorables para el desarrollo de las mismas. Hoy en

(*) Centro de Estudios de Corrosión. Facultad de Ingeniería. Universidad del Zulia, Maracaibo-Venezuela.

$\left(^{* *}\right)$ Laboratorio de Microbiología. Centro de Investigaciones del Agua. Universidad del Zulia, Maracaibo, Venezuela.

(***) Laboratorio de Electroquímica. Universidad de Los Andes, Mérida, Venezuela. 
día se confrontan diversas teorías sobre el mecanismo por el cual las BSR corroen algunos materiales, siendo la más clásica la de despolarización catódica propuesta por Von Wolzogen Kühr y Van Der Vlugt $^{\left[1{ }^{2}{ }^{2}\right]}$. Esta teoría establece que las BSR utilizan el $\mathrm{H}^{0}$ de una superficie metálica polarizada catódicamente para su respiración anaeróbica, a través del proceso desasimilatorio del sulfato (reducción de sulfato a sulfuro como vía energética) y, por consiguiente, el aumento de la velocidad de corrosión del acero se produce por efecto de la despolarización. Ésta y otras teorías, tales como la formación de una película poco adherente de sulfuro ferroso, catódica al metal base, que acelera la velocidad de corrosión y la acción directa de metabolitos agresivos como el $\mathrm{H}_{2} \mathrm{~S}$, se encuentran actualmente en estudio. Así, el objetivo de este trabajo fue evaluar la teoría de despolarización catódica, utilizando la técnica de permeación de hidrógeno de Devanathan y Stachurski ${ }^{[2]}$, una lámina inerte de paladio y la bacteria Desulfovibrio desulfuricans ssp. desulfuricans.

\section{DESARROLLO EXPERIMENTAL}

Los ensayos de permeación de hidrógeno se desarrollaron por duplicado en una doble celda tipo Devanathan y Stachurski ${ }^{[2]}$, siguiendo el montaje experimental de Ford y Michell ${ }^{[3 \text { y }}{ }^{4]}$ (Fig. 1), utilizando una lámina de paladio de $1,0 \mathrm{~mm}$ de espesor con un área de exposición de $3,14 \mathrm{~cm}^{2}$, una solución de $\mathrm{NaOH} 0,1 \mathrm{~N}$ (pH: 12,5) en una celda y, en la otra, el medio de cultivo ATCC $1249\left(\mathrm{MgSO}_{4}\right.$ :

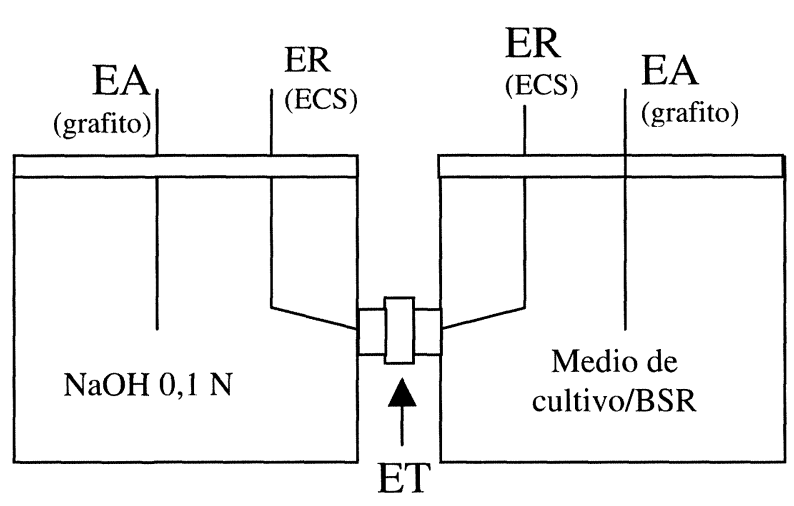

(Pd)

Figura 1. Doble celda electroquímica para evaluar permeación de hidrógeno.

Figure 1. Double electrochemical cell to evaluate hydrogen permeation.
2,0 gr; citrato de sodio: $5,0 \mathrm{gr} ; \mathrm{CaSO}_{4}: 1 \mathrm{gr}$; $\mathrm{NH}_{4} \mathrm{Cl}: 1 \mathrm{gr} ; \mathrm{K}_{2} \mathrm{HPO}_{4}$ : $2,5 \mathrm{gr}$; lactato de sodio: 3,5 gr; extracto de levadura: $1,0 \mathrm{gr}$; agua destilada: $1,0 \mathrm{gr} ; \mathrm{Fe}\left(\mathrm{NH}_{4}\right)_{2}\left(\mathrm{SO}_{4}\right)_{2}$ al $5 \%: 2$ \%; resarsurina al 0,2 \%: 0,1 gr; ascorbato de sodio al $5 \%$ : $1 \%$ y tioglicolato de sodio al $5 \%: 1 \%$, desaireado con nitrógeno gas de alta pureza, $\mathrm{pH}: 7,2, \mathrm{~T}: 37^{\circ} \mathrm{C}$, estéril o inoculado con la $D$. desulfuricans ssp. desulfuricans ATCC 7757). El inóculo correspondió al $10 \%$ del volumen de medio de cultivo a una concentración de $10^{8} \mathrm{cel} / \mathrm{ml}$.

Para la detección del hidrógeno permeado se aplicó un potencial de oxidación en los rangos de inmunidad del paladio $(-0,3 \mathrm{~V} \text { vs ECS })^{[2]}$, registrándose las correspondientes corrientes de oxidación o permeación (Fig. 2).

La validación del ensayo experimental, se logró aplicando una polarización catódica potenciostática al Pd expuesto en el medio de cultivo estéril, desde $-0,5 \mathrm{~V}$ hasta $-1,8 \mathrm{~V}$ vs ECS, con una velocidad de barrido de $50 \mathrm{mV}$ cada 5 a $10 \mathrm{~min}$, para lo cual se instaló el sistema electroquímico presentado en la figura 3. Una vez demostrado ésto, se desarrolló el ensayo de permeación sin polarización catódica (Fig. 4), registrando las respuestas de corriente de permeación y el potencial del paladio expuesto al desarrollo bacteriano. Posteriormente, se realizó el ensayo de permeación con polarización catódica (Fig. 3), manteniendo fijo un potencial de $1.000 \mathrm{mV}$ vs ECS por $17 \mathrm{~h}$, tanto en el medio de cultivo estéril como en el inoculado. Esto se hizo con la finalidad de establecer diferencias de permeación con y sin bacteria.

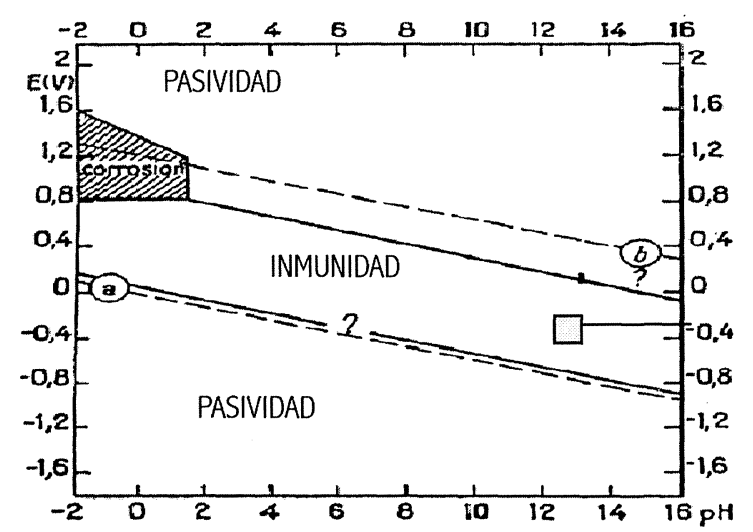

\section{口-Potencial aplicado vs ENH}

Figura 2. Diagrama de Pourbaix del Pd.

Figure 2. Pourbaix Diagram of Pd. 
Estudio de la teoría de despolarización catódica con permeación de hidrógeno y la bacteria Desulfovibrio desulfuricans M.F. de Romero, Z. Dugue, O.T. de Rincón, O. Pérez e I. Araujo

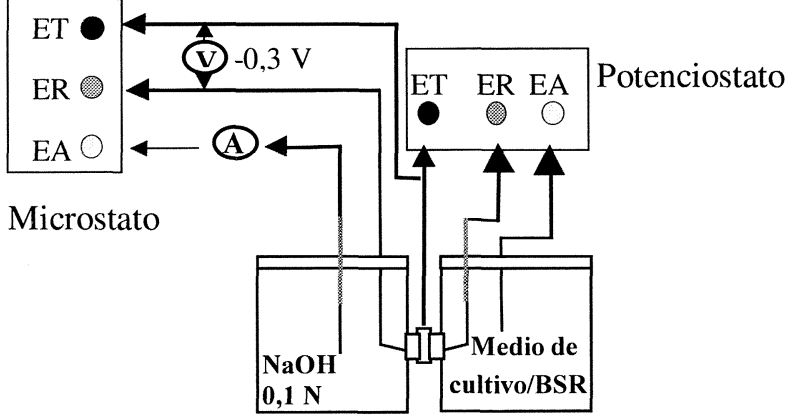

Figura 3. Celda de permeación con polarización catódica.

Figure 3. Permeation cell with cathodic polarization.

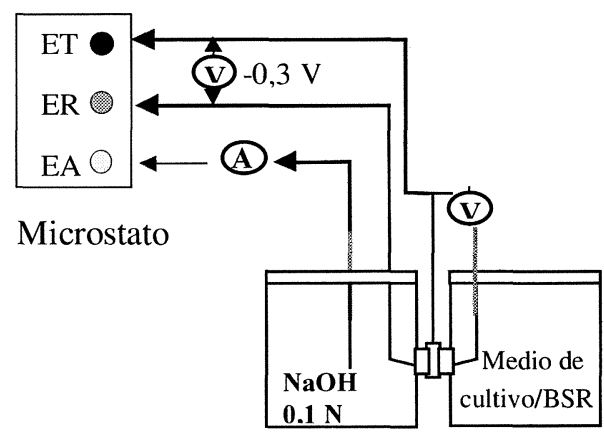

Figura 4. Celda de permeación sin polarización.

Figure 4. Permeation cell without cathodic polarization.

Antes de colocar nuevamente la lámina en la celda electroquímica, se desorbió el hidrógeno restante, se preparó la superficie con lija 600 y se colocó en etanol al $100 \%$ por 5 min con ultrasonido.

El crecimiento poblacional de la $D$. desulfuricans en la celda electrolítica durante los ensayos sin y con polarización, se evaluó por la técnica de dilución por extinción ${ }^{[6]}$. Adicionalmente, en la celda electrolítica con polarización, se cuantificó el desarrollo bacteriano por la técnica de placa vertida $^{[6]}$ y se caracterizó morfológicamente la $D$. desulfuricans utilizando Microscopía Electrónica de Barrido.

\section{RESULTADOS Y DISCUSIÓN}

Antes de iniciar la discusión de los ensayos de permeación, es importante analizar el crecimiento de la $D$. desulfuricans en la celda electrolítica. Al respecto se observó un buen desarrollo bacteriano sin y con polarización catódica. El contaje bacteriano reportó un crecimiento en ordenes similares para ambos ensayos (Tabla 1), determinándose a las $18 \mathrm{~h}$ valores entre $10^{9}-10^{10} \mathrm{cel} / \mathrm{ml}$.
Tabla I. Contaje de la $D$. desulfuricans en la celda electrolítica con y sin polarización catódica

Table I. Desulfovibrio desulfuricans ssp disulfuricaus growth with and without polarization

\begin{tabular}{ccc}
\hline $\begin{array}{c}\text { Tiempo } \\
\text { (h) }\end{array}$ & $\begin{array}{c}\text { Sin polarización } \\
\text { (cel/ml) }\end{array}$ & $\begin{array}{c}\text { Con polarización } \\
\text { (cel/ml) }\end{array}$ \\
\hline 0 & $10^{6}-10^{7}$ & $10^{6}-10^{7}$ \\
3 & $10^{7}-10^{8}$ & $10^{6}-10^{7}$ \\
6 & $10^{7}-10^{8}$ & $10^{7}-10^{8}$ \\
9 & $10^{8}-10^{9}$ & $10^{7}-10^{8}$ \\
12 & $10^{8}-10^{9}$ & $10^{7}-10^{8}$ \\
15 & $10^{8}-10^{9}$ & $10^{8}-10^{9}$ \\
18 & $10^{9}-10^{10}$ & $10^{9}-10^{10}$ \\
21 & $10^{9}-10^{10}$ & $10^{9}-10^{10}$ \\
24 & $10^{9}-10^{10}$ & $10^{9}-10^{10}$ \\
\hline
\end{tabular}

La figura 5 muestra un detalle de la biopelícula desarrollada sobre el Pd en uno de los ensayos de permeación sin polarización, observándose una alta densidad celular con la morfología típica del género utilizado (vibrios entre $1,0-1,5 \mu \mathrm{m})^{[6]}$, mientras que la figura 6 , muestra la curva de crecimiento poblacional en uno de los ensayos con polarización, donde se observa una curva típica con

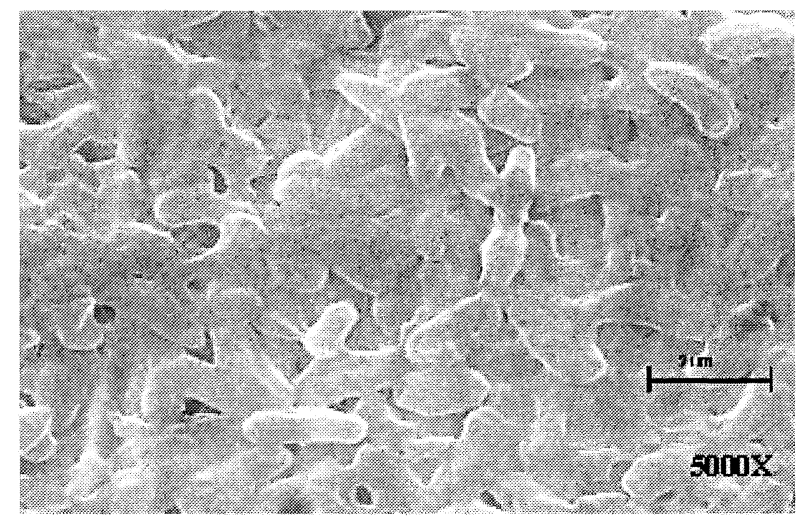

Figura 5. Biopelícula de $D$. desulfuricans sobre $\mathrm{Pd}$.

Figure 5. D. desulfuricans biofilm on Pd.

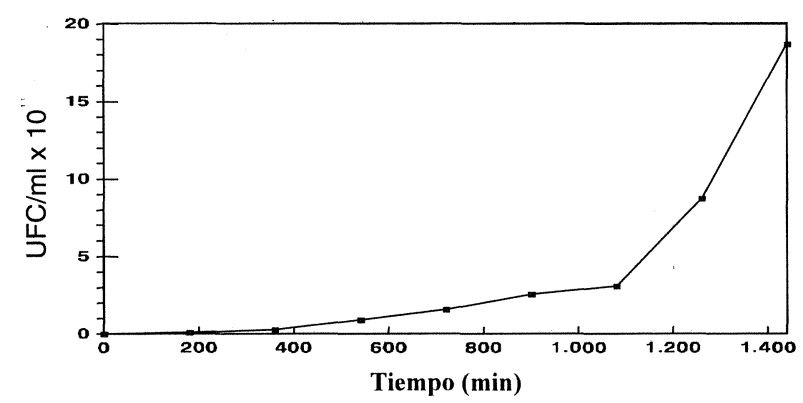

Figura 6. Crecimiento poblacional de la $D$. desulfuricans en la celda electrolítica con polarización catódica.

Figure 6. D. desulfuricans count in the electrolytic cell with cathodic polarization. 
su fase de adaptación hasta las $6 \mathrm{~h}$ y luego la fase exponencial con un desarrollo máximo de $19 \times 10^{11} \mathrm{UFC} / \mathrm{ml}$ a las $24 \mathrm{~h}$. Según estos resultados la bacteria D. desulfuricans se desarrolla independientemente de la polarización (Tabla 1), lo cual permite establecer que esta bacteria no necesita de superficies polarizadas catódicamente con $\mathrm{H}^{0}$ para la desasimilación del sulfato (respiración anaeróbica) y que ésto lo hace por encontrarse en un medio enriquecido con lactato, cuya fuente carbonada es oxidada en la pared celular de la bacteria en su proceso desasimilatorio generando hidrógeno atómico ${ }^{[4]}$.

En relación con los ensayos preliminares de permeación de hidrógeno con polarización catódica, éstos permitieron corroborar la efectividad de la técnica de permeación y del montaje experimental para evaluar si la BSR produce o no $\mathrm{H}^{0}$, ya que se confirmó que al existir $\mathrm{H}^{0}$ en la interfase del metal con el medio de cultivo, éste permea (Fig. 7). Con estos ensayos se determinó que en los primeros 80 min de polarización, la membrana de paladio se satura de $\mathrm{H}^{0}$ y a medida que continúa la polarización comienza a aumentar la corriente de permeación, alcanzándose valores de $1300 \mu \mathrm{A}$ $\left(414 \mu \mathrm{A} / \mathrm{cm}^{2}\right)$ a un potencial de $-1,8 \mathrm{~V}$ vs ECS. Esta corriente de permeación tan alta en el paladio se debe a que éste es un material que presenta una alta solubilidad de hidrógeno y que, además, no contiene fases secundarias o inclusiones como el acero que puedan reducir la velocidad de difusión aparente del metal ${ }^{[4]}$.

Una vez confirmada la aplicabilidad de la técnica, se realizaron los ensayos de permeación sin polarización catódica en medios de cultivos con bacterias (Fig. 8), determinándose que las corrientes de permeación fluctuaron entre 0 a $2 \mu \mathrm{A}(0$ a $0,64 \mu \mathrm{A} / \mathrm{cm}^{2}$ ), siendo esto reportado por otros investigadores como despreciable ${ }^{[4]}$. Estos resultados

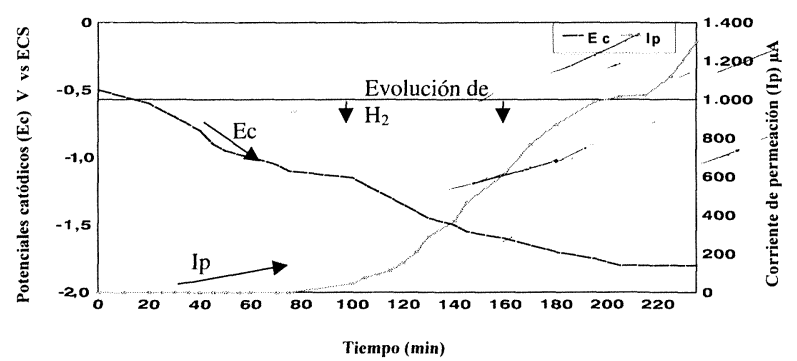

Figura 7. Corriente de permeación con polarización catódica hasta $-1,8 \vee$ vs ECS en medio estéril.

Figure 7. Permeation current with cathodic polarization up to $-1.8 \mathrm{~V}$ vs SCE in a sterile medium.

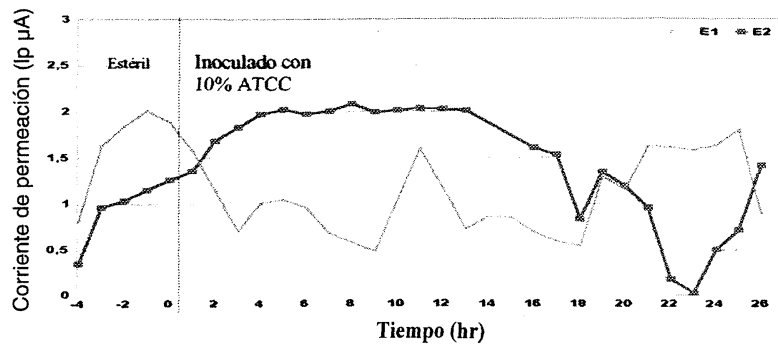

Figura 8. Permeación de hidrógeno por duplicado de la $D$. desulfuricans sin polarización.

Figure 8. D. desulfuricans count in the electrolytic cell, with and without cathodic polarization.

indican que esta bacteria, $D$. desulfuricans ssp. desulfuricans, no genera $\mathrm{H}^{0}$ extracelularmente capaz de permear, a pesar de que en su proceso metabólico produce organotróficamente, a nivel de su membrana, el $\mathrm{H}^{0}$ necesario para reducir los sulfatos a sulfuros, siendo éste excretado como $\mathrm{H}_{2} \mathrm{~S}$ por la bacteria, según las siguientes reacciones:

$$
\begin{gathered}
2 \mathrm{CH}_{3}-\mathrm{CHOH}-\mathrm{COONa}+2 \mathrm{H}_{2} \mathrm{O} \rightarrow \\
\rightarrow 2 \mathrm{CH}_{3} \mathrm{COONa}+2 \mathrm{CO}_{2}+8 \mathrm{H}^{0} \\
\mathrm{SO}_{4}^{=}+8 \mathrm{H}^{0} \rightarrow \mathrm{H}_{2} \mathrm{~S}+2 \mathrm{H}_{2} \mathrm{O}+2 \mathrm{OH}^{-}
\end{gathered}
$$

El $\mathrm{H}_{2} \mathrm{~S}$ así generado se disocia parcialmente en $\mathrm{HS}^{-}$y $\mathrm{H}^{+}$a un $\mathrm{pH}$ amortiguado de 7,2; luego, estos iones bisulfuros reaccionan con los iones ferrosos, provenientes de la sal de sulfato de amonio ferroso agregada al medio de cultivo, generando $\mathrm{FeS}$ que precipita sobre el metal y $\mathrm{H}^{+}$, según la siguiente reacción $^{[8]}$ :

$$
\mathrm{Fe}^{++}+\mathrm{HS}^{-} \rightarrow \mathrm{FeS} \downarrow+\mathrm{H}^{+}
$$

Según estas reacciones y los resultados obtenidos, se confirma que no hay producción neta de $\mathrm{H}^{0}$, siendo ésta la razón por la cual no se determinaron corrientes de permeación, ya que no ocurrió ningún tipo de reacción sobre el paladio que indujera a la reducción de los iones hidrógenos presentes en el medio.

En los ensayos de permeación con polarización catódica en medio estéril (Fig. 9) e inoculado (Fig. 10) se determinó lo siguiente:

En medio estéril, a los $165 \mathrm{~min}$, aproximadamente, se observaron corrientes máximas de permeación de 73 y $65 \mu$ A para cada ensayo, Ip1 e Ip2 respectivamente. Posteriormente, estas corrientes disminuyeron debido a la formación de una película de color ambar, producida por la precipitación de las sales existentes en el medio de cultivo y el 


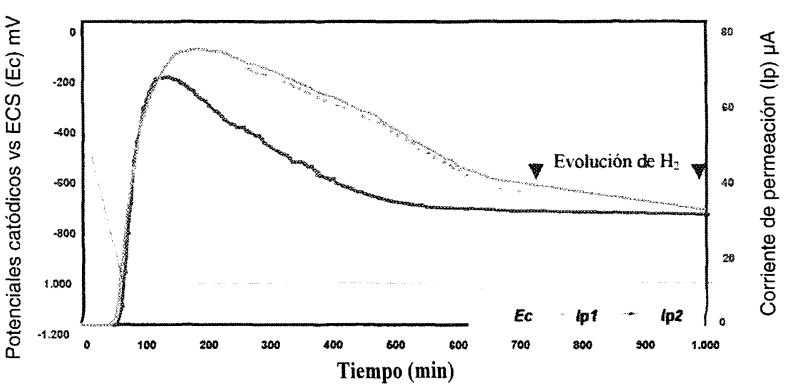

Figura 9. Corriente de permeación por duplicado manteniendo un potencial catódico de $-1.000 \mathrm{mV}$ vs ECS en medio estéril.

Figure 9. Duplicate permeation current maintaining a cathodic potential of $-1000 \mathrm{mV}$ vs SCE in a sterile medium.

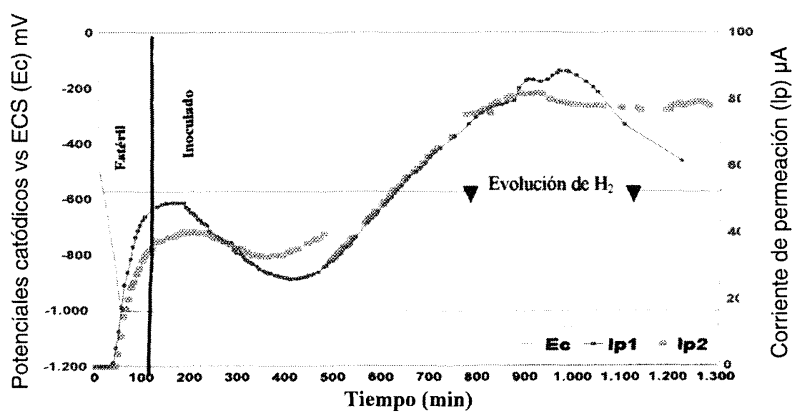

Figura 10. Corriente de permeación por duplicado manteniendo un potencial catódico de $-1.000 \mathrm{mV}$ vs ECS en medio inoculado.

Figure 10. Duplicate permeation current maintaining a cathodic potential of $-1000 \mathrm{mV}$ vs SCE in a inoculated medium.

aumento del pH en la interfase metal-solución, producto de la polarización inducida. Los análisis por MEB realizados posteriormente sobre una membrana de acero al carbono, sometida al mismo ensayo, indicaron que esta película está compuesta principalmente de fósforo y calcio.

En el medio inoculado, a los $175 \mathrm{~min}$, aproximadamente, de haberse iniciado el ensayo en medio estéril, se determinaron corrientes máximas de permeación de 50 y $40 \mu \mathrm{A}$ para cada ensayo, Ip1 e Ip2 respectivamente, y luego una disminución progresiva hasta $30 \mu \mathrm{A}$, aproximadamente, a los 470 min, observándose después un incremento progresivo hasta los $80 \mu \mathrm{A}$, aproximadamente, a los $1.000 \mathrm{~min}$. En este caso, la disminución de corriente hasta $30 \mu \mathrm{A}$ después de la inoculación, también puede deberse a lo explicado anteriormente en el ensayo sin bacterias y, adicionalmente, a la precipitación de una película no compacta de FeS con sitios activos donde las células bacterianas adheridas al paladio se desarrollan produciendo $\mathrm{H}^{+}$, el cual se reduce y permea, aumentando nuevamente la corriente de permeación a los $470 \mathrm{~min}$.

La figura 11 muestra, comparativamente, el comportamiento de la permeación en el medio estéril e inoculado, observándose claramente el efecto bacteriano sobre el aumento de la corriente de permeación, debido, como se dijo anteriormente, a la contribución de los protones $\left(\mathrm{H}^{+}\right)$generados por la disociación del sulfuro de hidrógeno, producido localmente por la BSR en su proceso metabólico, los cuales son reducidos rápidamente a $\mathrm{H}^{0}$ por el potencial catódico aplicado.

Para explicar el aumento de la corriente de permeación una vez inoculado el medio, también se analizó el efecto catódico de la película de $\mathrm{FeS}$ adsorbida junto con las bacterias sobre el paladio. Para ello, se revisaron las investigaciones realizadas por Ford et al. ${ }^{[4]}$ utilizando paladio y BSR. Ellos demostraron que sobre el paladio, la película de $\mathrm{FeS}$ inhibe la permeación en lugar de promoverla, cuando se burbujea $\mathrm{H}_{2}$ en la solución. Sin embargo, en el presente trabajo (Fig. 11), se observa que aumenta nuevamente la permeación después de los $470 \mathrm{~min}$, a pesar del FeS presente, lo cual puede ser atribuido al efecto local de las bacterias sésiles y a la polarización impuesta, que permite que los iones $\mathrm{H}^{+}$producidos por la bacteria sean reducidos. Según este análisis, sobre el paladio no ocurrirá permeación de hidrógeno en medios inoculados con esta bacteria, a menos que se induzca una polarización catódica, diferenciándose del acero al carbono, donde puede darse la permeación sin polarización catódica debido a que el material se corroe, reduciéndose los protones $\left(\mathrm{H}^{+}\right)$. En este caso, los sulfuros sí actúan como venenos catódicos, siendo esto perjudicial desde el punto de vista de la fragilización por hidrógeno del acero.

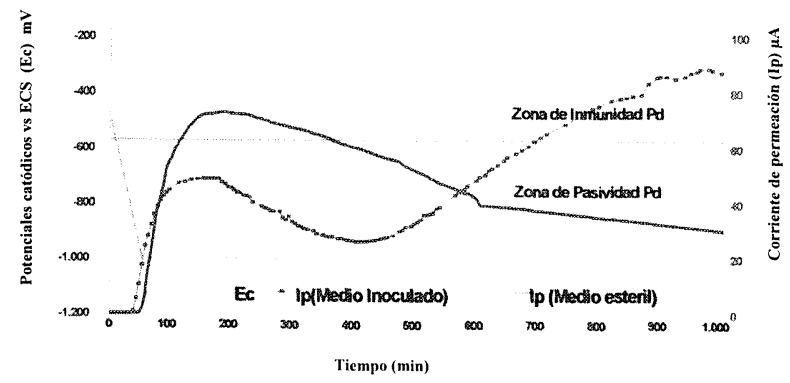

Figura 11. Curvas de permeación comparativas en medio de cultivo estéril e inoculado con polarización catódica.

Figure 11. Comparative permeation curves in sterile and inoculated medium with cathodic polarization. 
En la figura 11 también se observa un desfase de $20 \mu \mathrm{A}$, aproximadamente, entre las máximas corrientes de permeación, lo cual no tiene explicación. Sin embargo, lo más importante es la reproducibilidad de cada ensayo de manera independiente, lo que permite explicar el efecto bacteriano sobre la permeación de hidrógeno.

En la figura 12, se muestra cómo el incremento de las corrientes de permeación está asociado a la fase de desarrollo exponencial de la población bacteriana, lo cual confirma que existe una relación entre las BSR, $\mathrm{H}_{2} \mathrm{~S}$ y los iones $\mathrm{H}^{+}$con la corriente de permeación en una superficie de paladio polarizada catódicamente.

\section{CONCLUSIONES}

- La técnica de permeación de hidrógeno permite evaluar la actividad en la interfase biopelícula/metal, siendo de gran utilidad para estudios de mecanismos de MIC.

- La D. desulfuricans ssp. desulfuricans se desarrolla independientemente de que exista una superficie metálica polarizada catódicamente cargada de $\mathrm{H}^{0}$, ya que esta bacteria es capaz de ge-

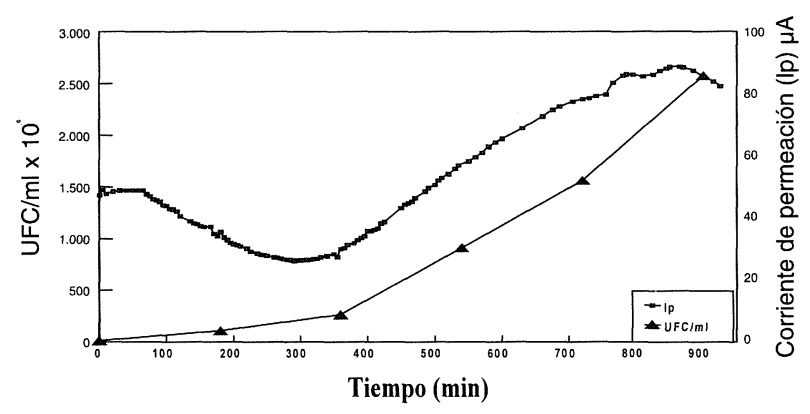

Figura 12. Relación de las corrientes de permeación con el crecimiento poblacional de la $D$. desulfuricans en la celda electrolítica.

Figure 12. Relationship of permeation currents and D. desulfuricans population growth in the electrolytic cell. nerar los $\mathrm{H}^{0}$ necesarios para reducir a nivel celular los sulfatos a sulfuros, sin producción neta de $\mathrm{H}^{0}$.

- La teoría de despolarización catódica no es el principal mecanismo de acción de las $D$. desulfuricans ssp. desulfuricans en el proceso de MIC. Por lo tanto, estudios de permeación utilizando lámina de acero al carbono serán realizados para aclarar dicho mecanismo.

- La D. desulfuricans no genera condiciones de reducción sobre el paladio para que el $\mathrm{H}^{+}$producido por las $\mathrm{H}_{2} \mathrm{~S}$ se reduzca y permee. No obstante, aumenta significativamente la permeación de hidrógeno bajo condiciones de polarización catódica, por lo cual es importante considerar esta actividad en aceros susceptibles a la fragilización por hidrógeno.

\section{Agradecimientos}

Al CONICIT por el apoyo financiero, a PDVSA INTEVEP (Dr. José Vera) por el apoyo técnico y al Laboratorio de Microbiología del Centro de Investigaciones del agua de la Universidad del Zulia por cedernos un espacio para instalar el Lab. de Corrosión Microbiológica.

\section{REFERENCIAS}

[1] W. Iverson, Mater. Perform. 233 (1984).

[2] M. Devanathan and Z. Stachurski, Proc. R. Soc. London 270 (1962).

[3] T. Ford and R. MiCHELl, Corrosion 89189 (1989).

[4] T.E. Ford, P.C. SCARson, T. Harris and R. Mitchel, J. Electrochem. Soc. 1374 (1991).

[5] J. Anderson, Structure of Metallic catalysts, Academic Press, INC, London, LTD, 1975.

[6] Bergey's Manual of Systematic Bacteriology, $9^{\text {th }}$ Ed. Wilkings \& Wilkings, Vol. 1, 1984.

[7] T. BRock and M. Madigan, Microbiologia. $6^{\mathbf{a}}$ Ed. Prentice Hall hispanoamericana C.A., México, 1993.

[8] J.R. VERA, Thesis for Doctor of Philosophy, Houston, Texas, May 1984. 